\title{
ENSINO DE ASTRONOMIA NOS ANOS INICIAIS: AS IDEIAS DOS ALUNOS À LUZ DO MÉTODO CLÍNICO PIAGETIANO
}

\author{
TEACHING ASTRONOMY IN THE EARLY YEARS: \\ STUDENTS' IDEAS IN THE LIGHT OF THE PIAGETIAN CLINICAL METHOD
}

\author{
LA ENSEÑANZA DE LA ASTRONOMÍA EN LOS PRIMEROS AÑOS: \\ IDEAS DE LOS ESTUDIANTES A LA LUZ DEL MÉTODO CLÍNICO PIAGETANO
}

ROBERTA CHIESA BARTELMEBS ${ }^{1}$

MARIA MILENA TEGON FIGUEIRA²

\section{RESUMO}

Neste artigo apresentamos os resultados de uma investigação com crianças do Ensino Fundamental acerca dos conteúdos de Astronomia. 0 trabalho foi desenvolvido no âmbito do projeto de pesquisa "Ensino de Astronomia Básica para o Ensino Fundamental". Apresentamos aqui os resultados de entrevistas realizadas com alunos de $5^{\circ}$ anos. Nosso objetivo foi o de compreender quais conhecimentos os alunos possuem sobre fases da Lua, estações do ano e eclipses. Foram entrevistados ao todo 9 estudantes de 5 escolas públicas. Para a realização das entrevistas nos pautamos no Método Clínico de Jean Piaget, estruturando a entrevista em três momentos: Questões abertas sobre 0 que as crianças já sabiam, realização de um desenho e utilização de material concreto. Nossos resultados apontam que há ainda uma preponderância de concepções alternativas sobre a compreensão efetiva dos conceitos envolvendo os astros, especialmente no que concerne a explicações que vão além da descrição dos fenômenos.

Palavras-chave: Educação em Astronomia. Ideias dos alunos. Ensino Fundamental. Método Clínico.

\section{ABSTRACT}

In this article we present the results of an investigation with elementary school children about the contents of Astronomy. The work was developed within the scope of the research project "Teaching Basic Astronomy for Elementary Education". Here we present the results of interviews with 5-year-old students. Our goal was to understand what knowledge students have about moon phases, seasons, and eclipses. In total, 9 students from 5 public schools were interviewed. For conducting the interviews, we were guided by the Clinical Method of Jean Piaget, structuring the interview in three moments: Open questions about what the children already knew, drawing and using concrete material. Our results indicate that there is still a preponderance of alternative conceptions on the effective understanding of the concepts involving the stars, especially regarding explanations that go beyond the description of the phenomena.

Keywords: Astronomy Education. Students' ideas. Elementary School. Clinical Method.

\section{RESUMEN}

En este artículo presentamos los resultados de una investigación con niños de primaria sobre los contenidos de la Astronomía. El trabajo se desarrolló en el marco del proyecto de investigación "Enseñanza de la astronomía básica para la educación primaria". A continuación, presentamos los resultados de las entrevistas a alumnos de 5 años. Nuestro objetivo era comprender qué conocimientos tienen los estudiantes sobre las fases lunares, las estaciones y

1E-mail: betachiesa@gmail.com

2 E-mail: milenategon@gmail.com 
Ios eclipses. En total, se entrevistó a 9 estudiantes de 5 escuelas públicas. Para la realización de las entrevistas nos guiamos por el Método Clínico de Jean Piaget, estructurando la entrevista en tres momentos: Preguntas abiertas sobre lo que los niños ya sabían, dibujando y utilizando material concreto. Nuestros resultados indican que aún existe un predominio de concepciones alternativas sobre la comprensión efectiva de los conceptos que involucran a los astros, especialmente en lo que respecta a explicaciones que van más allá de la descripción de los fenómenos.

Palabras-clave: Educación astronómica. Ideas de los estudiantes. Enseñanza fundamental. Método clínico.

\section{INTRODUÇÃO}

Desde antes das novas reformulações apresentadas pela Base Nacional Comum Curricular (BNCC), a Educação em Astronomia vem sendo cada vez mais debatida dentro do campo da Educação em Ciências. Atualmente, com a maior concentração de conteúdos desta área no Ensino Fundamental (BRASIL, 2018), nos voltamos às questões relativas ao ensino e a aprendizagem destes conceitos. Pesquisas apontam que muitos alunos não compreendem a Ciência que lhes é ensinada, mas formulam suas próprias ideias sobre os fenômenos científicos. Segundo Kitzberger, Bartelmebs e Rosa (2019), essas ideias alternativas que os alunos possuem costumam resistir ao ensino escolar (POZO; CRESPO, 2009).

Segundo Gomide e Longhini (2017), os alunos do Ensino Fundamental, costumam recorrer a explicações que vêm de suas experiências cotidianas. Neste sentido há conflito entre diferentes tipos de saberes quando, em uma aula, sua professora lhes diz que é o Sol quem gira ao redor da Terra e não o contrário.

De acordo com Langhi e Nardi (2004), as ideias mais comuns encontradas nos alunos, com relação à Astronomia, são: confundir as Fases da Lua com eclipses semanais; atribuir como causalidade das diferentes estações do ano à distância da Terra em relação ao Sol; possuir uma visão geocêntrica do Universo (NUSSBAUM, 1975); colocar estrelas entre os planetas do Sistema Solar (BARTELMEBS, SILVA, 2013); desconhecer o movimento aparente das estrelas no céu com o passar das horas; associar a presença da Lua exclusivamente ao céu noturno (LANGHI e NARDI, 2004); representar pessoas habitando o interior da Terra e acreditar que só existe gravidade onde houver ar ou alguma atmosfera. (RODRIGUES, SILVA, 2013; SCARINI, PACCA, 2006; CUBERO, 1997).

Tais modelos nem sempre correspondem ao conhecimento científico visto na escola. Isto porque, segundo Menino e Correia (2001, p. 99):

[...] essas concepções, estão fortemente enraizadas nas mentes dos alunos, o que conduz, muitas vezes as situações de insucesso escolar, principalmente porque diferem das ideias científicas veiculadas pela comunidade escolar. [...] concepções parecem extraordinariamente tenazes e resistentes a mudança, persistindo em alunos com vários anos de ensino das ciências e mesmo em professores.

Como essas ideias possuem significado, muitas vezes, é difícil mudar o conhecimento sobre determinado assunto, assim, faz-se necessário trabalhar com estas ideias, ou seja, criar situações em que os alunos possam manifestá-las e discuti-las, bem como as confrontar com a novas informações disponíveis e evidenciá-las experimentalmente, tomando consciência de que existem ideias diferentes das suas que servem para explicar os mesmos fenômenos.

Neste sentido, entendemos ser de extrema importância explorar o que sabem os alunos sobre os conteúdos de Astronomia que Ihes são ensinados nas aulas de Ciências. Especialmente os que estão concluindo o Ensino Fundamental I, que já tiveram contato com temas de Astronomia. Desta 
forma, a fim de compreender suas ideias sobre os conteúdos Fases da Lua, Eclipses e Estações do ano, elaboramos um protocolo de entrevista pautado no Método Clínico de Jean Piaget.

Este protocolo foi embasado em estudos anteriores do projeto de pesquisa "Ensino de Astronomia na Educação Básica", em desenvolvimento na Universidade Federal do Paraná. Apresentaremos a seguir o embasamento teórico da pesquisa, por se tratar de uma investigação com o Método clínico, explicaremos em detalhes o protocolo aplicado bem como as etapas da entrevista. Posteriormente apresentaremos uma a uma as entrevistas realizadas, com seus principais resultados. E, por fim, nas considerações finais, teceremos alguns comentários que acreditamos serem importantes para a evolução das investigações na área da Educação em Astronomia bem como do ensino de Ciências nos anos iniciais do Ensino Fundamental.

\section{A INVESTIGAÇÃO DO PENSAMENTO DOS ALUNOS COM O MÉTODO CLÍNICO}

Esta pesquisa, trata-se de um estudo exploratório de cunho qualitativo. Para coleta e análise dos dados, utilizamos o Método Clínico-Crítico, desenvolvido por Jean Piaget, o qual foi escolhido por ser flexível e suprir inúmeras possibilidades que podem surgir durante a entrevista. Este método pode ser definido, de acordo com Diniz (2011, p. 12), como uma "[...] démarche ativa de pesquisa e de intervenção, que considera os valores e as posições subjetivas no trabalho científico, além de permitir explicitar a relação do sujeito com o saber". Nesse sentido, podemos afirmar que o Método Clínico permite conhecer o pensamento do sujeito, revelando suas concepções e a ligação que elas têm com aquilo que nos diz durante uma entrevista (BARTELMEBS, et al., 2019).

De acordo com Piaget, uma das dificuldades em se fazer pesquisa com crianças, para desvendar suas concepções, é a questão da linguagem. Uma mesma palavra pode ter diferentes significados semânticos, e, terem interpretações diferentes para adultos e crianças. Assim, aponta o pesquisador: "O único meio de evitar essas dificuldades é variar as perguntas, fazer contra sugestões, em suma, renunciar a todo questionário fixo (PIAGET, 1947/2020, p. 11)". Neste sentido, a entrevista clínica com crianças tem 0 objetivo de variar as perguntas, para tentar apreender os sentidos que as crianças estão aplicando a determinadas explicações. Mesmo assim, alerta: "É tão difícil não falar demais quando se questiona uma criança, sobretudo quando se é pedagogo! É tão difícil não sugestionar (idem, p. 15)". Neste sentido, empenhamos nos, ao aplicar o método clínico, em deixar que a criança fale, mas em também intervir no momento adequado para incentivá-la a falar mais sobre 0 que pensa. É um trabalho difícil, que se aprende fazendo. Portanto, em nossas entrevistas também teremos comentários acerca de nossos próprios erros, a fim de alertar pesquisadores futuros sobre o que não fazer numa entrevista clínica.

Com relação aos tipos de respostas que podem ser desencadeadas durante a entrevista clínica, Piaget aponta algumas categorias:

Não-importa-0-que-ismo, surge quando a pergunta não suscita nada na criança, ela não sente vontade de responder nem de se divertir com a resposta.

Fabulação, ocorre quando a criança inventa uma história para sua resposta. Ela pode não ter clareza do que é o fenômeno investigado, mas sente prazer em fabular algo para responder à pergunta do(a) investigador(a).

Crença sugerida que ocorre quando a criança se esforça por responder, mas a pergunta é sugestiva, e a criança não faz uma reflexão própria para responder, segue a pista dada pelo(a) entrevistador(a). 
Crença desencadeada que é quando a criança responde com reflexão, a pergunta é nova para ela e ela busca em suas próprias bases cognitivas sua resposta.

E por fim, a crença espontânea que acontece quando a pergunta não é nova para a criança e a resposta resulta de uma reflexão anterior e original. Sobre as respostas do tipo crença espontânea: "A constância das respostas e a espontaneidade do relato em comparação com 0 caráter vago da pergunta denotam claramente uma crença espontânea, isto é, anterior à pergunta". (PIAGET, 1947/2020, p. 17).

No caso de nossa investigação acerca das fases da Lua, estações do ano e eclipses, nossa hipótese era a de que as crianças deveriam apresentar todas as crenças espontâneas acerca das perguntas pois, se tratava de conteúdos que elas já teriam visto em aulas de Ciências, e, portanto, não seriam conteúdos novos. Seria uma revisão de aulas anteriores.

Ainda na sua obra "A Representação do mundo na Criança", Piaget apresenta duas grandes etapas pelas quais a concepção acerca dos astros é construída pelas crianças. São elas: 0 artificialismo, segundo 0 qual os astros foram fabricados pelos seres humanos ou por seres míticos, deuses etc. E 0 animismo, ideia na qual os astros estão vivos, possuem sentimentos e desejos como os seres humanos e ocorre também a relação da participação dos humanos e dos astros, ou seja, a Lua é crescente, e, portanto, cresce, assim como as crianças também crescem. Para Piaget, "[...] a ideia central, ou seja, a crença de acordo com a qual os astros são concebidos como fabricados, deve ser considerada como correspondente a uma orientação de espírito espontânea da criança (PIAGET, 1947/2020, p. 218)".

Ao discutir 0 artificialismo e a influência religiosa que aparece em diversas respostas das crianças, Piaget propõe que: "no que diz respeito ao sol, à lua e às estrelas, o ensinamento religioso pode ter influenciado sobremaneira as crianças, dado que os astros estão muito mais próximos de um Deus que habita o céu do que os corpos situados na Terra (1947/2020, p. 219)". Bartelmebs e Silva (2013) apresentam um estudo no qual as crianças acreditavam que havia um céu onde anjos e Deus habitavam e outros céus dos astros. Porém, como afirma Piaget, não há necessariamente uma correlação direta entre 0 artificialismo religioso e a criação dessas ideias nas crianças uma vez que os dados de sua pesquisa revelam que mesmo crianças cujos pais não são religiosos também apresentam tendência ao artificialismo.

Ao analisar as entrevistas sobre a origem dos astros, Piaget faz um contraponto importante sobre 0 ensino religioso, que entendemos em nosso caso, poder se aplicar ao ensino de Ciências:

Em suma, o ensino religioso não é recebido pela criança de modo passivo, mas é deformado e assimilado de acordo com três tendências preexistentes a esse ensino. Essas tendências são, precisamente, a tendencia a criar participações, a tendência artificialista e a tendência animista, cuja importância na mentalidade da criança as pesquisas anteriores demonstraram. (1947/2020, p. 221)

Ou seja, segundo os estudos de Piaget e colaboradores, num primeiro estádio os astros são fabricados, e as crianças entendem que há uma origem humana ou divina para a sua existência. Num segundo e terceiro estádios, eles têm uma origem parcial e posteriormente natural. Há assim uma evolução de suas concepções. Talvez hoje essa relação seja ainda mais rápida, uma vez que desde 0 
primeiro ano do Ensino Fundamental já se ensina conceitos de Astronomia para as crianças. E, desde muito antes, imagens de uma Terra solta no espaço já permeiam seu dia a dia.

\section{SOBRE NOSSOS PARTICIPANTES E A INTERRUPÇÃO DA PESQUISA}

Ao todo, no ano de 2019 , foram realizadas 15 entrevistas, com estudantes de faixa etária entre 8 a 11 anos, todos de escolas públicas de um município da região Oeste do Paraná (Tabela 01). Neste artigo apresentaremos os resultados de 9 entrevistas relativas a alunos(as) do $5^{\circ}$ ano. Devido ao isolamento social decorrente da Pandemia da Covid 19, não foi possível dar sequência as entrevistas de outros(as) alunos(as) para complementar os estudos deste protocolo. Portanto, apresentaremos a seguir a análise feita das primeiras aplicações das entrevistas, com seus erros e acertos, entendendo que ambos fazem parte do processo de construção do conhecimento científico.

Tabela 1 - Dados dos sujeitos participantes.

\begin{tabular}{cccc}
\hline Protocolo & Idade & Sexo & Série \\
\hline $\mathbf{0 1}$ - NY & 10 & $\mathrm{~F}$ & $5^{\circ} \mathrm{Ano}$ \\
$\mathbf{0 2}$ - KI & 10 & $\mathrm{~F}$ & $5^{\circ} \mathrm{Ano}$ \\
$\mathbf{0 3}$ - GU & 10 & $\mathrm{M}$ & $5^{\circ} \mathrm{Ano}$ \\
\hline $\mathbf{0}$ - SM & 11 & $\mathrm{M}$ & $5^{\circ} \mathrm{Ano}$ \\
$\mathbf{0} \mathbf{0}-\mathbf{P I}$ & 10 & $\mathrm{~F}$ & $5^{\circ} \mathrm{Ano}$ \\
$\mathbf{0 6}$ - BIA & 10 & $\mathrm{~F}$ & $5^{\circ} \mathrm{Ano}$ \\
$\mathbf{1 0}$ - BIBI & 10 & $\mathrm{~F}$ & $5^{\circ} \mathrm{Ano}$ \\
\hline $\mathbf{1 4}$ - LUC & 10 & $\mathrm{M}$ & $5^{\circ} \mathrm{Ano}$ \\
\hline $\mathbf{1 5}$ - LEI & 10 & $\mathrm{~F}$ & $5^{\circ} \mathrm{Ano}$ \\
\hline
\end{tabular}

Fonte: construção dos autores.

As entrevistas foram realizadas nas dependências das escolas, com a autorização dos pais e ou responsáveis e da equipe diretiva das escolas. Foram gravadas em áudio e depois transcritas. Participavam de cada entrevista dois bolsistas do projeto e a orientadora. Solicitava-se à equipe diretiva que nos cedesse um espaço na escola, onde de preferência só houvesse a criança e os entrevistadores. Assim, individualmente as crianças foram entrevistadas, no entanto, pela dinâmica do contexto escolar, era comum sermos interrompidos por uma ou outra entrada na sala. 0 tempo de entrevista era geralmente de uma hora. As entrevistas ocorreram em três etapas: Num primeiro momento para deixar a criança mais à vontade, eram feitas perguntas gerais. Posteriormente estimulávamos que elas falassem livremente do tema fases da Lua, eclipses ou estações do ano. Posteriormente elas eram convidadas a realizarem um desenho da temática, durante 0 qual era questionada. E por fim, ela deveria responder algumas perguntas utilizando um material concreto previamente organizado para essa entrevista (Figura 01). 
Figura 01 - Material concreto utilizado nas entrevistas.

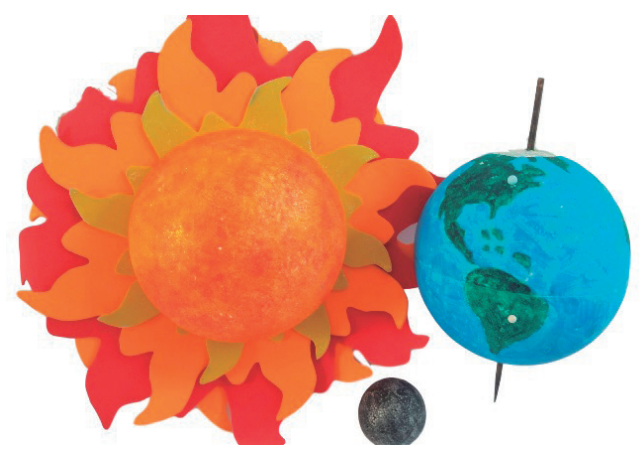

Fonte: construção dos autores.

\section{DISCUSSÃO DOS RESULTADOS}

Escolhemos apresentar neste artigo os resultados das entrevistas realizadas com as crianças de turmas do $5^{\circ}$ ano por ser 0 último ano do Ensino Fundamental I, fase em que as crianças têm mais contato com conteúdo de Astronomia em seu currículo escolar. E por ser o último ano do Ensino Fundamental I, marcando uma fase de encerramento de uma etapa da Educação Básica.

Apresentaremos partes das entrevistas com nossos comentários e discussões teóricas pertinentes para a interpretação dos resultados. Optamos por apresentar um por um dos protocolos por haver particularidades em cada uma das entrevistas que podem enriquecer 0 olhar das(os) professoras(es) sobre o pensamento de seus(as) alunos(as) sobre os temas de Astronomia.

\section{PROTOCOLO 01 - NY}

Entrevistador(a): eu queria que você me falasse qualquer coisa que você sabe sobre a Lua, o que você sabe sobre a Lua?

Sujeito 01: Nossa eu não sei quase nada sobre a Lua.

Entrevistador(a): Você costuma ver ela, assim.

Sujeito 01: Não! Não sou acostumada.

Posteriormente ela relata que na outra escola lembra de um professor de ciências falar sobre a Lua, que ela é bem grande. Para motivar a menina a falar sobre suas concepções sobre as fases da Lua, segue-se o diálogo, até que ela relata: E quando ela fica pela metade, alguma coisa assim, eu acho que ela fica se escondendo, sabe! Atrás das nuvens!

Essa concepção aparece nos estudos de Piaget e colaboradores (1947) quando investigam a origem dos astros e as fases da Lua. É natural que as crianças, nessa etapa, tratem os astros como tendo vontade própria, por isso quando NY fala que a Lua se esconde, está atribuindo a esse astro uma vontade e ação que é próprio do ser vivo.

$\mathrm{Na}$ tentativa de desafiar essa ideia de que são as nuvens que cobrem a Lua causando suas fases, a entrevistadora segue com a pergunta: 
Entrevistador(a): Você tinha falado que a Lua ficava escondida às vezes atrás das nuvens né?

Sujeito 01: $E$.

Entrevistador(a): E isso é quando ela está assim?

Sujeito 01: Quando ela está pela metade!

Entrevistador(a): Aham!

Sujeito 01: Também, acho que, as nuvens entram na frente dela.

Entrevistador(a): Daí a gente não consegue ver?

Sujeito 01: $E$.

Entrevistador(a): E tu acha que isso acontece a noite inteira, ou só num pedacinho da noite?

Sujeito 01: Ah, eu acho que é a noite inteira!

Entrevistador(a): Hum, a noite inteira. E você já viu alguma vez, que não tinha nuvem e que não tinha Lua também!

Sujeito 01: Já!

Entrevistador(a): É! E o que você acha que aconteceu naquele dia?

Sujeito 01: A eu acho que nesse dia, é porque tava num temporal, em um tempo de chuva, onde de madrugada choveu, daí entra um monte de nuvem na frente da Lua e não dá pra ver nada!

Nesse momento NY fabula uma resposta nova, tentando explicar por que ocorre Lua nova. Quando solicitamos que ela utilize o material concreto, ela nos fala que:

Entrevistador(a): Você... como que você acha que fica a Terra e Lua, lá no espaço? Sujeito 01: A eu acho que a Terra fica assim, e a Lua fica aqui assim, aí como a Lua gira em volta da Terra.

Entrevistador(a): Há, a Lua gira em volta da Terra!

Sujeito 01: É eu acho que é isso! Daí ela fica girando, girando e girando. [...] Mas quando eu tô andando de carro, parece que o Sol segue a gente!

Entrevistador(a): É?

Sujeito 01: Aham! Eu acho que a Terra fica girando assim, devagar e o Sol só fica parado assim. Ilumina metade, depois a outra metade. (referindo-se ao dia a e noite).

Porém, mais adiante NY volta a confabular uma história quando não consegue explicar a ocorrência do eclipse solar (na verdade ela afirma desconhecer esse tipo de eclipse) embora explique com certa clareza a ocorrência do eclipse lunar:

Sujeito 01: Sim, eu já vi (um eclipse lunar), e acho muito legal.

Entrevistador(a): E como você acha que acontece? Pode fazer se você sabe, se você quiser fazer (referindo-se a utilizar o material concreto).

Sujeito 01: Eu acho que a Lua entra na frente do Sol e daí ele fica, e o Sol parece que fica preto, alguma coisa assim! Ou fica vermelho! Daí só dá pra ver com óculos escuros! [...] 0 Sol pode entrar na frente da Lua?

Entrevistador(a): É, não é bem assim (elipse solar). Daí o Sol não entra na frente da Lua, mas acontece a mesma coisa que acontece com a Lua, acontece com o Sol! Sujeito 01: $E$. 
Entrevistador(a): Aham. Você não sabia? (referindo-se ao eclipse solar).

Sujeito 01: Não, não sabia! Ah, não sei! Eu acho que, a luz do Sol, ela ilumina, e daí as nuvens entram na frente da Lua, e eu acho que o Sol e a Lua se encontram, as escondidas.

Entrevistador(a): É...

Com relação as estações do ano, NY repete uma das concepções alternativas mais clássicas entre professores, alunos e população em geral sobre a ocorrência das estações do ano:

Sujeito 01: Eu acho que quando ta verão, é, a gente fica mais perto do Sol.

Entrevistador(a): Assim?

Sujeito 01: É, mais perto do Sol! E daí como a Terra vai girando, e demora, acho que seis meses pra Terra girar, não sei.

Entrevistador(a): Aham.

Sujeito 01: Daí, tipo assim, aqui a gente fica meio que, a Terra gira bem devagar, então a gente fica mais perto do Sol, e quando ela vai girando pra cá, parece que é, a primavera, aham, dai quando a gente vira, mais assim, parece que é o frio, por causa que o Sol não ta pegando. Entendeu?

Entrevistador(a): Entendi.

Sujeito 01: Daí aqui assim, é o outono.

Na verdade NY repete um pouco a mesma explicação que usou para o dia e a noite, mas não percebe isso, e mantém sua teoria. Assim, com relação as estações do ano, percebemos que ela mantém uma explicação alternativa que ela percebe ter sentido. Aparentemente, se eu afasto a Terra do Sol, ela recebe menos calor, portanto, faz sentido que faça frio. A questão é que nos dois hemisférios do planeta temos estações do ano diferente num mesmo período, isto é, não faz inverno em todo o planeta. Talvez uma boa pergunta nesse momento teria sido essa: Mas é inverno em todo planeta? É possível que essa nova informação fizesse NY refletir sobre teoria e talvez criar uma explicação. Com relação aos eclipses, ao não saber explicar ela fabula um caso entre o Sol e a Lua. Evidentemente ela ainda transita entre o pensamento anímico e 0 científico.

Por muito tempo essa concepção alternativa persistiu nos livros didáticos e mesmo na mídia (OSTERMANN, MOREIRA, 1992). A ausência de atividades práticas nas aulas de ciências, que façam "o elo entre as perspectivas da observação e do modelo, ou seja, antropocêntrica e heliocêntrica" (LAGO, ANDRADE, LOCATELLI, 2017, p. 24) acabam por possibilitar que tais concepções persistam.

PROTOCOLO 02 - KI

Nesta entrevista a criança não estava muito disposta a falar sobre a Lua, no início suas respostas foram sempre negativas ou relativas a não saber ou não lembrar do assunto:

Entrevistador (a): Essa noite que você está desenhando, é uma noite que, em que a Lua está como?

Sujeito 02: Cheia!

Entrevistador (a): E você sabe o que, que acontece para ela ficar cheia?

Sujeito 02: Não. 
Entrevistador (a): Você já reparou que às vezes tem essa Lua cheia que você desenhou aí bem bonita né. Mas às vezes não tem né.

Sujeito 02: Uhum.

Entrevistador (a): Tu sabe. Tu tem alguma explicação para isso?

Sujeito 02: Não.

Entrevistador (a): Tu já pensou assim sobre isso, tipo, por que será que às vezes tem a Lua lá, e às vezes não tem?

Sujeito 02: Nunca pensei.

No sentido de perceber se a crença relativa as nuvens, podia ser contestada por outras crianças, perguntamos para Kl:

Entrevistador (a): Teve um colega seu que falou que tem nuvens que tapam a Lua, você concorda?

Sujeito 02: Concordo!

Entrevistador (a): Mas já aconteceu alguma vez, em alguma noite, que não tinha nuvem e que não tava chovendo e você olhou para o céu e não tinha Lua?

Sujeito 02: Nunca.

Entrevistador (a): Nunca aconteceu isso, sempre tinha a Lua ou quando não tem então sempre tem nuvens?

Sujeito 02: Sim.

A criança, ficou evidente para nós depois, não estava se sentindo instigada a participar da entrevista. Mais tarde soubemos que o horário da entrevista foi marcado no mesmo horário das atividades de educação física. Assim, privamos (sem querer!) a aluna de sua atividade preferida na escola. As demais respostas sobre as estações do ano e os eclipses sempre foram negativas, no sentido de que ela não se recordava ou não sabia. Fica uma importante reflexão para quem desejar repetir este tipo de atividade, cuidar que os horários das entrevistas não suprimam alguma atividade da qual a criança goste de participar.

\section{PROTOCOLO 03 - GU}

Gu demonstrou bastante interesse nas questões apresentadas. Sobre as formas que a Lua apresenta enquanto está em fases:

Entrevistador(a): Então pode falar não tem problema!

Sujeito 03: Eu já vi a Lua cheia!

Entrevistador(a): E como que é a Lua cheia?

Sujeito 03: Inteira!

Entrevistador(a): A inteira bem brilhante né?

Sujeito 03: É. (Pensando....) Tem aquela! A esqueci!

Entrevistador(a): Tem a cheia que você falou antes $e$ ?

Sujeito 03: Aquela meia!

Entrevistador(a):Aí ela fica só pela metade né?

Sujeito 03: E tem uma mais fina ainda. 
Entrevistador(a): E tem vezes que não tem Lua, que você olha para o céu e não vê a Lua?

Sujeito 03: Todo dia tem Lua.

Entrevistador(a): Todo dia tem Lua, nunca acontece de não ter então? E tem Lua de dia também?

Sujeito 03: Não.

Com relação ao dia e a noite, GU apresenta uma concepção alternativa de que quem se move são o Sol e a Lua e não a Terra. Durante a utilização do material concreto instigamos ele para perceber suas concepções:

Entrevistador(a): Então aqui temos o Sol, o Sol fica parado ou ele se movimenta? (utilizando material concreto)

Sujeito 03: Se movimenta para ficar noite ele gira ao redor.

Entrevistador(a): Ele vem para cá então.

Sujeito 03: Eu acho que sim.

Entrevistador(a): Então eu tenho a Terra a Lua aqui e ele vem para cá. E a Terra ela fica fazendo assim?

Sujeito 03: Depois de manhã vem o Sol e depois ele vai para o outro lado!

Na tentativa de confrontar essa concepção, durante a realização do experimento com o material concreto, fizemos a simulação do dia e da noite para GU:

Entrevistador(a): Dia, e a Terra está girando né, e agora eu e você estamos para 0 lado de lá, e agora é dia ou noite?

Sujeito 03: Noite.

Entrevistador(a): Noite, beleza. Você acha que tem necessidade do Sol se mexer, trocar de lado?

Sujeito 03: Sim, porque senão, não fica de noite.

Ou seja, para GU não bastou demonstrar o que se estava falando. 0 conteúdo ainda não encontrou uma estrutura cognitiva que lhe comporte. Ele ainda mantém a crença de que o Sol precisa se mover para haver dia e noite. Retomando ainda a questão apresentada por NY, a respeito das nuvens taparem a Lua e formarem as fases, questionamos GU:

Entrevistador(a): Então eu vou te dizer algo que uma colega sua me falou que quando aparece só um pedacinho da Lua ela disse que as nuvens tapam a Lua para que ela não apareça, você concorda?

Sujeito 03: Sim.

Entrevistador(a): Em algumas vezes você lembra de olhar para o céu ser de noite não ter nuvem e não está chovendo, ser uma noite quente de verão por exemplo, com o céu estrelado, e que você viu que a Lua tá só um pedacinho e não tem nuvem tapando, já aconteceu algum dia?

Sujeito 03: Já.

Entrevistador(a):E aí como é que fica essas histórias das nuvens que taparia a Lua?

Sujeito 03: Aí eu não sei. 
Com relação aos eclipses GU não afirma o mesmo que suas outras colegas, pois acredita que como 0 Sol é muito maior do que a Lua é impossível que ela o tape durante um eclipse:

Entrevistador(a): Teve uma colega sua que falou que o eclipse do Sol acontece porque a Lua tapa o Sol. Você acha que isso é possível? Você concorda?

Sujeito 03: 0 Sol é bem maior que a Lua!

Entrevistador(a): Então seria impossivel da Lua tapar o Sol?

Sujeito 03: Eu acho que sim.

Com relação as estações do ano, GU tem uma vivência particular que o faz compreender que existem diferentes estações ao redor do mundo ao mesmo tempo. Porém, ele não recorda a explicação das aulas e não elabora nenhuma na hora da entrevista:

Sujeito 03: Eu não sei se lá em Portugal, porque eu nasci lá. Não sei como é não. Mas eu vejo meu pai lá, eu vi que quando aqui é calor, lá é frio e quando aqui é frio, lá é calor. Entrevistador(a): Exatamente, acontece ao contrário. Vamos colocar você pra viajar, você vai lá pra Portugal, vamos dizer que é aqui assim, em algum lugar.

Sujeito 03: (risadas...)

Entrevistador(a): Você vai estar sentindo frio com o seu pai, e eu vou estar sentindo maior calor aqui. E porque, que você acha que acontece isso?

Sujeito 03: A não sei.

Entrevistador(a): Você acha que tem alguma coisa a ver com o Sol?

Sujeito 03: sim.

Entrevistador(a): Tem alguma coisa a ver com o Sol. Só que você ainda não saberia me explicar?

Sujeito 03: Não.

GU nos apresenta um exemplo claro de um aluno que ao concluir o Ensino Fundamental I, a despeito de todas as aulas de conteúdos de Astronomia que já teve, não assimilou as respostas científicas para certas questões. A começar pelo movimento do Sol e a estagnação da Terra, já temos um conflito para explicar as estações do ano, por exemplo. Ele compreende que há diferenças na temperatura da Terra no verão de diferentes hemisférios, por vivência familiar, mas não elaborou ainda uma explicação para a ela. Talvez para GU seria necessário, mais adiante nos estudos de Ciências, reelaborar essa questão, e provavelmente com maior facilidade, ele aceitaria a ideia de que não há uma só temperatura no verão e no inverno, e isso poderia facilitar sua aprendizagem sobre a inclinação do eixo da Terra. Mas primeiro, ele precisa movimentar a Terra e "estacionar" o Sol em seu sistema.

PROTOCOLO 04 - SM

Para SM, a Lua é visível durante 0 dia e a noite, contrariando 0 que geralmente as crianças falam nesse sentido:

Entrevistador(a): Sim!? Você consegue ver, observar essas fases durante o dia? durante a noite?

Sujeito 04: Durante a noite! 
Entrevistador(a): Só durante a noite?

Sujeito 04: Não, de dia, antes é, quando tá é, bem de manhã aqui na escola dá pra ver a Lua!

Entrevistador(a): De manhã só?

Sujeito 04: De manhã, e um pouco mais tarde!

Entrevistador(a): Um pouco mais tarde, que horas assim mais ou menos?

Sujeito 04: Umas 16:30!

Entrevistador: Mas por que ela muda de fase? Sabe me dizer?

Sujeito 04: Não.

Entrevistador(a): Não? Tem alguma idéia? Do que poderia ser.

Sujeito 04: Talvez, da posição da Lua com a Terra!

Entrevistador(a): Pode ser!

Sujeito 04: Com o Sol!

Para SM, as fases da Lua possuem direta relação com o movimento da Lua, da Terra e do Sol no espaço. E vai além ao conferir movimento de rotação à Lua, o que é algo menos comum entre as crianças de sua idade (relativas as que entrevistamos durante nossas pesquisas):

Entrevistador(a): A Lua também faz esses movimentos?

Sujeito 04: Faz, em volta da Terra!

Entrevistador(a): Em volta da Terra, e ela só tem esse movimento?

Sujeito 04: Não, em volta dela também!

Porém, com relação as explicações sobre eclipse, SM não soube responder com tanta exatidão, apenas remeteu a uma relação de iluminação entre Sol, Terra e Lua:

Sujeito 04: Eclipse Lunar e o eclipse Solar.

Entrevistador(a): Os dois, o Solar é do?

Sujeito 04: Do Sol que reflete na Lua e na Terra!

Entrevistador(a): Aham!

Sujeito 04: E o lunar é quando, Sol reflete na Terra, que reflete na Lua!

Já com relação as estações do ano, SM apresenta a concepção alternativa da distância e proximidade da Terra com relação ao Sol:

Sujeito 04: 0 movimento de translação!

Entrevistador(a): É de translação. Mas o que acontece?

Sujeito 04: Porque a Terra gira em torno do Sol, e faz uma vez ficar quente, outra vez ficar mais frio!

Entrevistador(a): Ah! Entendi! - E por que uma vez fica quente outra vez fica frio?

Sujeito 04: Por causa da posição da Terra!

Entrevistador(a): Posição da Terra? Em relação ao Sol?

Sujeito 04: Sim.

Entrevistador(a): Mas o que, que acontece? Que tipo de posição?

Sujeito 04: É que tem uma parte, que ela fica um pouco mais longe, aí tem uma parte que ela chega mais perto! A outra ela está um pouco perto e a outra também! 
Aqui, novamente, poderíamos ter explorado com a pergunta sobre os hemisférios, para ver 0 que a criança responderia. Como SM já construiu uma base mais sólida sobre o movimento da Terra, a relação com o Sol, poderia ser uma boa oportunidade de fazê-lo refletir sobre este ponto. Vale ressaltar aqui que em várias entrevistas a orientadora não estava presente, e, portanto, os bolsistas conduziram a entrevista. Sendo assim, entrevistadores em treinamento, houve momentos que poderiam ter sido mais bem explorados. Mas que certamente servem de aprendizagem para quem deseja aplicar o método clínico com seus alunos.

\section{PROTOCOLO 05 - PI}

Durante a realização do desenho sobre as fases da Lua, a entrevistadora percebe que a criança pinta a Lua em duas cores diferentes:

Entrevistadora: Hum... Por que você está pintando a lua de duas cores?

Sujeito 5: Porque esta parte aqui, a gente não consegue ver. Aqui ela está mais escura, mas mesmo assim ela está ali.

Entrevistadora: Hum. E sabe por que isso acontece? Por que uma parte fica mais clara e outra não?

Sujeito 5: Por causa da... a parte que a gente vê iluminada da lua.Por exemplo, aqui a lua está aqui e o sol aqui, o sol vai clarear esta parte aqui, mais ou menos, da lua. A gente só vai enxergar essa parte, mas a outra parte ainda está clareada. A gente enxerga só um pouco, a metade, por causa da posição da lua...da... da lua e da Terra.

Ao utilizar o material concreto PI já sabe diferenciar as fases da Lua da ocorrência de um eclipse:

Entrevistadora: Então fica o sol a lua e a Terra.

Sujeito 5: Sim, né. Não alinhado.

Entrevistador: Não alinhados. Tá. E por que não alinhados?

Sujeito 5: Porque se fosse alinhado seria um eclipse solar.

Entrevistadora: Hum. Beleza então... tá você me falou antes sobre o eclipse, né?

Quais tipos de eclipses que existem?

Sujeito 5: Vish são bastante. Mas os principais são o solar e o luar.

Entrevistadora: Tá e você consegue me mostrar como que acontece?

Sujeito 5: 0 solar é quando a lua está entre a Terra e o sol. Assim, formando tipo um anel em volta da lua quando a gente estiver na Terra. E o lunar é quando a lua... a lua tá atrás... a Terra está entre o sol e a lua, assim, a lua fica com a sombra da Terra, fica refletida com a sombra da Terra. Pelas fotos que eu vi, fica mais ou menos um pouco avermelhado a lua.

Com relação as estações do ano, PI argumenta que:

Sujeito 5: São... Como eu posso explicar?! Elas são fases que, elas dividem os climas aqui na Terra.

Entrevistadora: Tá.

Sujeito 5: E ela acontece porque... pelo movimento de translação da Terra. 
Porém, apesar de conceitualmente ela saber sobre o movimento de translação, que possivelmente aprendeu com seus professores de ciências, não sabe explicar como ocorrem as estações do ano no modelo concreto:

Entrevistador: Tá. E você está deixando a Terra assim por quê?

Sujeito 5: Por causa para iluminar aqui no Brasil. Então, aqui seria verão e aqui no Japão seria inverno.

Entrevistadora: E você já percebeu que quando é verão aqui é inverno aqui?... Você já ouviu falar?

Sujeito 5: É, eu já ouvi isso. Que um fica no Hemisfério norte e o outro no Hemisfério sul.

Entrevistadora: E por que isso acontece? Você sabe me dizer?

Sujeito 5: Porque... é... por causa do movimento de rot... rotação da Terra. Que uma parte fica para cima e outra para baixo, e o sol está iluminando em baixo. Então quando está em cima, aqui embaixo ficaria inverno.

E para perceber que a criança está num processo de assimilação dos conceitos recebidos em aula, há conhecimento sobre a inclinação do eixo de rotação da Terra:

Entrevistador: Você acredita que ela é reta assim no espaço?

Sujeito 5: Não, ela é inclinada. Mais ou menos.

Entrevistador: Então você acredita que esse eixo de inclinação interfere em alguma coisa?

Sujeito 5: Um pouco... Onde o sol vai iluminar. (referindo-se a incidência maior ou menor de calor na Terra).

Pl é um exemplo de uma criança que já está num avançado processo de consolidação desses conceitos relativos à Astronomia. Ela já percebe a Terra como uma bola solta no espaço, com um eixo de inclinação, e que já diferencia o eclipse lunar das fases da Lua, por exemplo. Assim percebemos que crianças de uma mesma faixa etária, que estão em um mesmo nível escolar, possuem diferenças no nível de assimilação dos conteúdos escolares. E isso pode estar vinculado tanto a suas vivências pessoais quanto a forma pela qual esses conteúdos Ihes foram ensinados nas aulas.

PROTOCOLO 06 - BIA

BIA faz a representação das fases da Lua no desenho, utiliza lápis amarelo para representar a luz do Sol refletindo na superfície lunar. A criança relaciona aspectos do seu dia a dia ao responder quando a Lua fica visível no céu, não apenas pelo período noturno:

Entrevistador: Nova... Hum. É, e essas fases você consegue observar de dia, de noite?

Sujeito 6: Bom se for um dia com muita chuva, tem muita nuvem.

Entrevistador: Tem muita nuvem...

Sujeito 6: Daí eu não consigo ver.

Entrevistador: Uhum.

Sujeito 6: Mas quando... está bastante ensolarado, assim, eu consigo. 
Entrevistador: Consegue ver a lua... Então ela não aparece só de noite, ela aparece de dia também?

Sujeito 6: $E$.

Entrevistador: Igual você esta me dizendo.

Sujeito 6: Não de dia, de meio dia, assim, eu não consigo ver direito.

Entrevistador: Entendi.

Sujeito 6: Mas acho que tem. Dá para ver... Mas quando estou indo, assim, para a escola eu consigo ver.

BIA tem o costume de observar o céu noturno e demonstra curiosidade com relação a isso, ela tem uma vivência particular que fomenta essa curiosidade pelo céu:

Sujeito 6: Eu gosto de ficar olhando para o céu.

Entrevistador: Aaa, quem não gosta, é? (risadas)

Sujeito 6: Uma vez eu estava com meus primos e colocamos o colchão lá fora só para ficar enxergando as estrelas.

Diferente das crianças entrevistadas por Piaget (1947/2020, p. 230), como na entrevista de LUG, criança de 12 anos, que afirma que a Lua não é sempre redonda pois ela é "cortada pelo meio". "Perto da noite ela é redonda e de dia é cortada pelo meio" quando questionado pelo motivo disso ele afirma: "porque é de dia, e que nesse momento essa outra parte da lua parte para outro país”. Com relação as fases da Lua, BIA demonstra que para seu nível de conhecimento, não é possível que a Lua se divida:

Entrevistador: Então, você desenhou ela inteira, aqui para mim, você está tentando me dizer que essa é a parte que você consegue ver, mas que ela é inteira.

Sujeito 6: É. Ela é inteira, não dá para cortar, né...

Quando vai manipular o material concreto, BIA apresenta alguma dificuldade para poder representar a posição dos astros no espaço:

Sujeito 6: ... Eu não consigo saber... Por causa que... Eu não sei se a cheia ela fica aqui.

Entrevistador: Entendi... É, não tem problema, só me explica porque você sempre coloca aqui, assim.

Sujeito 6: Para mim que a lua, ela não fica aqui em cima. Ela fica dos lados.

Entrevistador: Dos lados?! Ah, entendi. Então você coloca elas dos lados para representar os movimentos delas?

Sujeito 6: $\dot{E}$.

Entrevistador: Ah. E como ela faz esse movimento?

Sujeito 6: (mexe na lua).

Entrevistador: E a Terra?

Sujeito 6: Terra, ela gira em volta de si mesma e em volta do sol.

Entrevistador: Em volta do sol. E o sol?

Sujeito 6: 0 sol fica parado. 
Quando ela explica os eclipses consegue representar com o material concreto o eclipse solar, mas confunde-se no eclipse lunar, talvez esse seja um pouco mais complexo por conta da representação que fazemos das fases da Lua:

Entrevistador: Pode representar, então, como ficaria? 0 lunar e 0 solar?

Sujeito 6: 0 solar eu acho que fica assim... E o lunar assim.

Entrevistador: Ahh. Por que que o lunar fica assim?

Sujeito 6: Por causa que 0 sol bate na lua, e a lua... faz tipo uma sombra para a lua. Uma sombra para a gente na Terra e faz uma sombra para a lua.

Entrevistador: E 0 solar?

Sujeito 6: Ele... 0 sol... A lua fica na frente do sol, mas daí... a lua fica na frente da... da Terra.

Já com relação as estações do ano, BIA reproduz uma concepção alternativa bastante comum com relação a ocorrência desses fenômenos:

Entrevistador: Quando vai mais na piscina, muito bom. É... sabe me representar como ficaria? Por que ocorre as estações do ano?

Sujeito 6: Olha, é a distância do sol ...da Terra... Da distância do sol da Terra.

Entrevistador: Do sol da Terra?

Sujeito 6: É. Quando fica inverno o sol se... o planeta ou o sol se distância, que eu não lembro quem se distância. É... quando é verão ....aproxima

Quando 0 entrevistador retoma a questões tentando fazer com que a criança expresse um pouco melhor suas concepções, BIA confunde os movimentos da Terra e demonstra que ela sabe os nomes dos movimentos, mas não compreende ainda como eles ocorrem:

Entrevistador: É, né. Você tinha falado dos movimentos da Terra também, né? Quais eram os movimentos mesmo?

Sujeito 6: Translação e rotação.

Entrevistador: E, qual desses movimentos influência nas estações?

Sujeito 6: Acho que é o translação.

Entrevistador: 0 translação? qual é o movimento que o de translação faz?

Sujeito 6: Ela gira em torno de si mesma (vai falando diminuindo a voz)... Eu não sei se ela faz uns giro...

Entrevistador: Hum, você sabe quais são os nomes, né, mas não me dizer.

Sujeito 6: $\dot{E}$.

Entrevistador: Você pode representar para mim? Como... O movimento que influencia nas estações?

Sujeito 6: Eu acho que é o... que é o que ela gira em torno de si mesma.

Entrevistador: Gira em torno de si mesma. Entendi. É... esse que gira em torno de si mesma, dura quanto tempo?

Sujeito 6: Acho que... um ano.

Essa entrevista reforça uma ideia que vem se generalizando nos estudos de didática das ciências na área de ensino: Não adianta ensinarmos apenas os conceitos para as crianças, elas precisam 
compreender como esses fenômenos ocorrem, quais relações eles apresentam entre si. Somente decorar o nome de movimentos não permite que saibamos como eles ocorrem. A mobilização cognitiva que se exige ao decorar ou ao compreender um fenômeno são bem distintas.

\section{PROTOCOLO 10 - BIBI}

Na entrevista de Bibi tivemos a impressão de que, nesta escola, a professora havia preparado as crianças para a entrevista. Isso porque, como o(a) leitor(a) poderá verificar, as respostas eram quase automáticas, cheia de detalhes na nomenclatura, e, mesmo após se tentar mudar 0 assunto, a criança insistia em seguir falando aquilo que lhe vinha à memória. Desta forma, vamos apresentar as respostas, mas temos que levar em conta que essas crianças não estavam apenas com o conhecimento obtido ao longo dos anos, e sim, com uma atividade feita antes da entrevista para que elas pudessem "responder corretamente" nossas perguntas.

Entrevistadora: Você antes disse sobre os Eclipses, o que você lembra dos Eclipses?

Sujeito 10: Eu? Você quer saber do Lunar ou Solar?

Entrevistadora: Fala dos dois então.

Sujeito 10: 0 Lunar é quando tá o Sol, a Terra e a Lua, e só acontece os Eclipses quando os três estão na linha de nodos. E o Eclipse Solar é a sombra da Terra na Lua, o Eclipse Solar é quando o Sol, a Lua e a Terra estão na linha de nodos e faz a sombra na Terra. E quando se tem um Eclipse, tem a órbita da Lua na Terra, né. Entrevistadora: Uhum.

Sujeito 10: E quando a Lua tá um pouco mais longe, a gente chama isso de Apogeu, que quando a Lua tá mais longe da Terra faz-se o Eclipse Anular e quando ela tá do outro lado, no Perigeu, é acontece o Eclipse Parcial que leva... às vezes pode ir até 1 hora. Depois tem os grãos de Baily e depois o anel de diamante, e esses são os últimos segundos antes do Eclipse Total. E daí, nós temos o caminho da totalidade, né, a Umbra, e se você não tiver na totalidade, tem a Penumbra, que quanto menos você ver o grão, não... e se você tiver na Penumbra, menos você vai ver o Eclipse Solar.

[...]

Entrevistadora: Só o Lunar? Então eu trouxe aqui uma representação, um Solzinho, a Terra e a Lua. Vamos voltar então para as fases da Lua, você sabe me explicar como ocorre utilizando isso? (No caso a representação).

Sujeito 10: É, mais ou menos assim. Quando a Lua.... Ah, e eu esqueci de falar que o Eclipse Solar só acontece na Lua Nova e o Lunar só na Lua Cheia.

Grifamos alguns termos que normalmente as crianças não costumam utilizar para nos falar sobre os eclipses. Pode ser que sua professora julgou que nossas entrevistas tinham um caráter avaliativo. Isso aconteceu com outras turmas que essa mesma docente ministra aulas de ciências e nas quais realizamos entrevistas (com $2^{\circ}, 3^{\circ}$ e $4^{\circ} \mathrm{s}$ anos).

No entanto, ao utilizar o material concreto Bibi, ao representar as fases da Lua, confundiu-se na representação da Lua Crescente (quando ela representou de fato a lua nova). Ao representar as estações do ano ela também apresentou estar bastante confiante nas suas respostas: 
Entrevistadora: Você sabe me explicar como elas ocorrem?

Sujeito 10: Mais ou menos, porque a Terra tá assim, inclinada e daí, por exemplo, 0 Verão é quando o Sol, os raios estão pegando aqui na Terra, né, na região Sul e aqui em cima como não pega muito Sol é o Inverno.

Entrevistadora: Uhum.

Sujeito 10: E dai tem os dois lados, né, ai é ao contrário....

Entrevistadora: Então finge que a gente tá aqui no Brasil (referindo-se ao material concreto).

Sujeito 10: Sim, por exemplo, se o Sol tá pegando aqui vai ser Primavera e Outono. Se o raio estiver pegando aqui, vai ser Verão e Inverno. E o inverso, se o Sol tiver pegando aqui vai ser Inverno e Verão.

Também tivemos aqui uma situação de que a entrevistadora é uma pesquisadora em treinamento, então, nem sempre as perguntas aprofundaram ou causaram desequilíbrio nas respostas de Bibi. Por exemplo, poderia-se ter explorado o caso dos eclipses e tê-la feito explicar de diferentes maneiras com o material concreto. Questioná-la qual a diferença entre as luas nova e cheia e os eclipses (uma vez que na representação destas fases, ela se confundiu ao utilizar o material concreto, representando uma pela outra). Fica neste caso a reflexão, como fazer perguntas para crianças que são "preparadas" para nossas entrevistas? Até que ponto suas respostas são validas para nossa pesquisa? E, por fim, como evitar que os docentes pensem que é preciso preparar seus alunos para nossas entrevistas?

\section{PROTOCOLO 14 - LUC}

Para Luc, a Lua está sempre visível no céu, especialmente a noite, ainda defende a ideia de que durante o dia não é possível ver a Lua. Ele identifica suas fases e consegue explicá-las ao entrevistador:

Entrevistador: Já aconteceu de você olhar para o céu e não ver a Lua?

Sujeito 14: Não.

Entrevistador: Toda noite tem Lua?

Sujeito 14: Sim toda a noite, e daí num dia ela tá num jeito das fases.

Entrevistador: Hamm, e quais são as fases, você sabe?

Sujeito 14:Lua cheia, lua crescente, lua nova e lua minguante.

Entrevistador: Beleza, e as outras duas fases que você falou, cheia e minguante, como você imagina que sejam elas?

Sujeito 14: A lua cheia ela é tudo preta e lua minguante ela é iluminada.

Entrevistador: lluminada como?

Sujeito 14: Ela é iluminada inteira, só a lua cheia que não é.

Entrevistador: Mas então na lua cheia é tudo preta, não dá para ver a Lua?

Sujeito 14: Mas eu nunca vi a lua cheia.

Entrevistador: $E$ a lua aparece quando?

Sujeito 14: de noite.

Entrevistador: Então de dia a Lua não aparece é só a noite?

Sujeito 14: (Aluno balança concordando) Sim. 
Luc confunde os nomes das fases cheia e nova. E mantém sua ideia inicial de que a lua só é visível a noite. Quando solicitado a fazer a representação com os modelos concretos, ele não consegue explicar muito bem como correm as fases da Lua, mas afirma:

\section{Entrevistador: Ela faz algum movimento?}

Sujeito 14: Ela fica girando em volta da Terra

Entrevistador: Entendi, e você me disse que a Terra gira também, isso ocorre ao mesmo tempo, ou como que é?

Sujeito 14: Minha professora disse que quando a Terra ta girando a Lua também fica girando.

A resposta: "Minha professora disse" nos remete a um argumento da autoridade que ele reconhece como correta. Não necessariamente seja algo no qual ele também acredite. Já houveram casos de crianças que, no meio de uma entrevista, disseram: "A professora me falou, mas eu não acreditei" (FIGUEIRA, 2019, p. 37).

Com relação aos eclipses Luc encontra dificuldades de explicá-los, esbarrando muitas vezes em conceitos que ele "aprendeu" nas aulas mas não assimilou muito bem:

Entrevistador: E no eclipse Solar o que acontece? Se hoje tivesse um eclipse solar por exemplo o que a gente veria?

Sujeito 14: (Desenhando...) No eclipse solar o Sol fica aqui a Lua fica, e no eclipse Lunar a Lua fica aqui.

Entrevistador: No eclipse Lunar fica assim então, Sol, a Lua e a Terra (lendo a representação feita no desenho).

Sujeito 14: Eclipse solar, o Sol a Terra e a Lua.

Entrevistador: E daí o que acontece no eclipse? Por exemplo o eclipse solar?

Sujeito 14: Não sei.

Entrevistador: Você disse que no eclipse Solar fica a Sol a Terra e a Lua, toda vez que eles tiverem nessa posição ocorre o eclipse?

Sujeito 14: Só de vez em quando.

Entrevistador: E por que só de vez em quando?

Sujeito 14: Não sei.

E por fim, com relação as estações do ano ele não soube responder como elas ocorriam nem com o desenho nem com o material concreto. Quando lhe foi questionado sobre as estações do ano ele esqueceu quais elas eram. Assim, como ele esqueceu o nome delas, pensamos que isso interferiu na sua memória e na sua confiança para continuar a responder as questões.

\section{PROTOCOLO 15 - LEI}

Da mesma escola que Luc, Lei não consegue responder como ocorrem as fases da Lua, afirmando apenas que existe uma em que ela fica cheia e outra em que parece uma "banana". Essa metáfora muitas vezes é utilizada nas aulas de ciências para explicar as fases da Lua (ou melhor, nominá-las).

No decorrer da entrevista, quando ainda se versava sobre as fases da Lua, Lei afirma que o Sol gira: 
Entrevistador(a): Ele gira? (referindo-se ao Sol)

Sujeito 15:é.

Entrevistador(a): Mas ele gira como?

Sujeito 15: Assim ó, bem devagarzinho.

Entrevistador(a): Gira em torno do que? Ou não, gira só em torno dele?

Sujeito 15: Da Terra.

Entrevistador(a)Há, o sol gira em torno da terra?

Sujeito 15: A Terra gira em torno do Sol... não, acho que é o Sol mesmo, que gira em torno da Terra.

Na sequência Lei apresenta duas alternativas para as fases da Lua, e confabula uma teoria de que a Lua pode ir para outro planeta, ou ainda, que a Lua nunca fica baixa no horizonte:

Entrevistador(a): cheia?

Sujeito 15: Aham, mas daí ela vai estar em outro planeta, a Lua! Não vai ver mais. Entrevistador(a): Ah, então quando ela estiver em outro planeta, a gente não vê a Lua aqui?

Sujeito 15: Não.

Entrevistador(a): Não, beleza, ok. Alguma vez você já olhou pro céu e não viu a Lua? Sujeito 15: Sim.

Entrevistador(a): Sim, então a gente não vê ela, porque ela vai estar em outro planeta? Sujeito 15: Tem dias que ela não aparece, só estrela.

Entrevistador(a): Só estrela, verdade, e por que será?

Sujeito 15: Porque eu acho que ela está muito baixa, não espera, a lua nunca baixa, mas o sol não estava iluminando ela o bastante para ela aparecer, daí ela fica bem escondida! Bem quietinha!

A confabulação faz parte das respostas das crianças quando elas "parecem se divertir" (PIAGET, 1947/2020) com aquilo que o entrevistador Ihe pergunta. Não é necessariamente uma mentira, a criança pode simplesmente ainda transitar entre 0 mundo imaginário e 0 real, e, para explicar 0 mundo real, inventar algumas histórias que remetam ao animismo. Ir para outro planeta, talvez, não signifique a Lua vá embora do céu da Terra. Pode ser que, para Lei, o céu seja compartilhado com todos os planetas do Sistema Solar, por isso, seria possível que a Lua estivesse aqui numa noite e em outra aparecesse no céu de Marte, por exemplo. É uma possibilidade, mas teríamos que questionar diretamente a criança sobre isso.

Lei, assim como Bia, consegue explicar satisfatoriamente a ocorrência do eclipse solar no material concreto, mas não o lunar:

Sujeito 15: 0 sol tava aqui e a lua aparecia na frente do sol, daí o sol parava de iluminar a terra, e a terra ficava toda escura.

Entrevistador(a): Ah... e como que chama esse eclipse?

Sujeito 15: Eclipse solar!

Entrevistador(a): E tem outra forma de eclipse?

Sujeito 15: 0 eclipse lunar, mas eu não sei te explicar esse não. 
Mas no decorrer da entrevista, voltou-se a esse tema tentando obter uma explicação mais aprofundada da criança, e voltou-se ao tema de o Sol girar ao redor da Terra, quando Lei apresenta uma recordação do que aprendeu com a professora de ciências, e que ainda está assimilando:

Entrevistador(a): Então tá, então é o Sol que gira em torno da Terra?

Sujeito 15: aham

Entrevistador(a): E daí o eclipse lunar?

Sujeito 15: A Terra gira em torno do Sol.

Entrevistador(a): Não entendi agora, o Sol gira em torno da Terra e....

Sujeito 15: A Terra gira em torno do Sol. Os dois "se gira".

Entrevistador(a): Os dois ficam girando ao mesmo tempo, tudo junto?

Sujeito 15: É...

Entrevistador(a): Ah entendi. Legal!

Sujeito 15: Porque a Terra tem dois jeitos de girar, assim, e assim.(Demonstrando no material concreto).

Entrevistador(a): Em torno do Sol ou não?

Sujeito 15: Eu acho que o Sol, fica parado, ele só gira, ele só vai fazer assim ó!

Entrevistador(a): Não entendi a sua, ideia, me explica melhor!

Sujeito 15: Ó a professora de ciências me explicou assim, quando eu estava no quarto ano! - Que a Terra tem dois movimentos, assim!

Entrevistador(a): uhum

Sujeito 15: e assim!

Entrevistador(a): sim!

Sujeito 15: E o Sol, fica parado, agora que eu lembrei, girando só assim! (Representa o movimento de rotação no Sol).

Entrevistador(a): Só em torno dele mesmo?

Sujeito 15: $E$.

Entrevistador(a): Então ele não gira em torno da terra? Ou gira?

Sujeito 15: Gira.... ele tem os dois movimentos.

Quando confrontado sobre o movimento de rotação e translação que supostamente o Sol faria me torno da Terra, vemos que Lei tenta conformar uma lembrança ao eu já estava falando ao entrevistador. Claramente a menina está assimilando esse conteúdo em sua estrutura cognitiva, mas ainda há conflito. Poderia-se ter questionado se ela vê o Sol se mover ao longo do dia e o que isso tem a ver com o movimento que ela estava tentando representar.

\section{CONSIDERAÇÕES E APONTAMENTOS}

Diversas pesquisas sobre concepções alternativas têm demonstrado a existência de concepções alternativas em alunos e professores sobre diferentes temas, inclusive os de Astronomia. Essas concepções alternativas, quando não levadas em consideração pelo professor, podem levar ao insucesso escolar dos alunos, isto porque estas concepções fazem sentido e estão fortemente enraizadas na mente do aluno, dificultando ou até mesmo impossibilitando a compreensão do conhecimento científico (MENINO; CORREIA, 2005). Nesse sentido, o objetivo central desse artigo foi identificar e compreender as ideias que os alunos têm sobre as fases da Lua, eclipses e estações do ano. 
Com relação as fases da Lua, de forma geral, os alunos entendem que as fases da Lua são ocasionadas pelas nuvens do céu noturno, e, corroborando com pesquisas de outros autores, muitos acreditam que a Lua somente é visível no céu à noite. Além disso, alguns alunos não reconhecem a existência de noites em que a Lua não é visível, alguns alunos inclusive, ao cogitar essa possibilidade, fabulam histórias para explicar a ausência do astro no céu.

Sobre os eclipses com exceção da aluna que parece ter decorado a respostas para a entrevista, percebemos de forma geral que os alunos confundem a posição e 0 movimento dos astros, o que gera confusões em explicar os eclipses solar e lunar, em alguns casos as estudantes conseguem explicar o eclipse lunar, mas não consegue explicar o solar, como é o caso das alunas Lei e Bia.

Além disso, em nosso trabalho também constatamos que as estações do ano são explicadas pelos alunos muito mais pelas alterações climáticas, e por vezes, quando aparece alguma explicação relacionada com a distância da Terra em relação ao Sol, ou ainda relacionam ao movimento de translação, mas não sabem como explicar essa relação.

Identificamos também diversas ideias que poderiam ter sido mais bem exploradas pelos pesquisadores, no entanto a falta de experiência e a dificuldade de se trabalhar com o método clínico influenciaram em alguns momentos das entrevistas, fica ainda como sugestões para as futuras entrevistas, ter 0 cuidado de verificar se 0 horário da entrevista não irá priva o(a) aluno(a) de participar de alguma atividade que ele(a) goste.

Acreditamos ser extremamente importante a identificação e compreensão das ideias dos alunos. Isso porque esse conhecimento permite ao professor pensar práticas metodológicas mais efetivas, que partam dessas ideias para que possam complexificar o conhecimento de senso comum dos alunos até atingirem um nível de elaboração mais complexo, cada vez mais próximo das explicações científicas para os fenômenos da Astronomia.

\section{REFERÊNCIAS}

BARTELMEBS, R. C. SILVA, J. A. Representações de crianças do Ensino Fundamental acerca do conceito de céu a partir do Método Clínico-Crítico. In: Shème. Revista Eletrônica de Psicologia e Epistemologia Genética. v. 5, n. 2, p. 4-23, 2013. Disponível em: https://bit.ly/3rrkQNe. Acesso em: 20 mar. 2020.

BARTELMEBS, R. C.; KITZBERGER, D. 0.; JEZUS, M. T.; FIGUEIRA, M. M. T.; PANDINI, C. A. Modelos de significação sobre conteúdos de Astronomia: Considerações acerca de um estudo com professores de Ciências da Educação Básica. In: Revista Eletrônica de Psicologia e Epistemologia Genéticas Schème, v. 11, n. 2, p. 34-79. 2019. Disponível em: https://bit.ly/3xFub50. Acesso em: 02 fev. 2021

BRASIL. Ministério da Educação. Secretaria da Educação Básica. Base Nacional Comum Curricular (BNCC). Ministério da Educação, Brasilia, DF: MEC/SEB, 2018. Disponível em: https://bit.ly/3d5JGtJ. Acesso em: 17 abr. 2019.

CUBERO, Rosario. Cómo trabajar con las ideas de los alumnos. 4. ed. Sevilla: Díada, 1997.

DINIZ, M. 0 Método Clínico e sua utilização na pesquisa. In: Revista Espaço Acadêmico, Edição Especial, v. 10, n. 120, p. 9-21, 2011. Disponível em: https://bit.ly/3obaJtJ. Acesso em: 26 abr. 2017.

FIGUEIRA, M. M. T. Ensino de Astronomia básica para deficientes visuais. 2019. 56p. Trabalho Final de Curso (Licenciatura em Ciências Exatas). Universidade Federal do Paraná, Setor Palotina. 
GOMIDE, H. A.; LONGHINI, M. D. Modelos mentais de estudantes dos anos iniciais do Ensino Fundamental sobre 0 dia e a noite: um estudo sob diferentes referenciais. Revista Latino-Americana de Educação em Astronomia, n. 24, p. 45-68, 2017. Disponível em: https://doi.org/10.37156/RELEA/2017.24.045. Acesso em: 02 jan. 2021.

KITZBERGER, D. 0.; BARTELMEBS, R. C.; ROSA, V. . As diferentes concepções sobre as fases da lua de alunos dos oitavos anos do Ensino Fundamental de uma escola pública. In: Revista Latino-Americano de Educação em Astronomia, n. 28, p. 67-93, 2019. Disponível em: https://doi.org/10.37156/RELEA/2019.28.067. Acesso em: 17 mar. 2020.

LAGO, L.; ANDRADE, R. de; LOCATELLI, R. Astronomia no ensino de ciências da natureza. São Paulo: Livraria da Física, 2017.

LANGHI, R. e NARDI, R. Um estudo exploratório para a inserção da Astronomia na formação de professores dos anos iniciais do Ensino Fundamental. In: Revista Tecné episteme y Didaxis, n. 16, 2004. Disponível em: https://doi.org/ 10.17227/ted.num16-5543. Acesso em: 19 fev. 2020.

LANGHI, R. Educação em Astronomia: da revisão bibliográfica sobre conceções alternativas à necessidade de uma ação nacional. In: Cad. Bras. Ens. Fís., v. 28, n. 2: p. 373-399, ago. 2011. Disponível em: https://doi.org/10.5007/ 2175-7941.2011v28n2p373. Acesso em: 02 fev. 2020.

MENINO, H.L.; CORREIA, S.O. Concepções alternativas: ideias das crianças acerca do sistema reprodutor humano e reprodução. Educação \& Comunicação, n. 4, p. 97-117, s.d, 2005. Disponível em: https://bit.ly/3d7nDCH. Acesso em: 10 fev. 2020.

NUSSBAUM, J.; NOVAK, J., D. An assessment of childrens concepts of the Earth utilizing structural interviews. In: Science Education, v. 60, n. 4, p. 535-550, 1976. Disponível em: https://doi.org/10.1002/sce.3730600414. Acesso em: 15 de out. 2020.

OSTERMANN F.; MOREIRA, M. A. A física na formação de professores do ensino fundamental. Porto Alegre: Ed. Universidade/UFRGS, 1999.

PIAGET, J. A representação do mundo na criança. 5. ed. São Paulo: Editora ideias e letras, (1947) 2020.

POZO, J. I.; CRESPO, M. A. G. A aprendizagem e o ensino de ciências: do conhecimento cotidiano ao conhecimento científico. 5. ed. Porto Alegre: Artmed, 2009.

RODRIGUES, T. C. T.; SILVA, A. M. M. da. As ideias dos alunos sobre o formato da Terra e as fases da Lua. In: Anais do V Encontro Estadual de Ensino de Física, Porto Alegre, 2013. Disponível em: https://bit.ly/308ZSR9. Acesso em 04 mar. 2019.

SCARINCI, A. L.; PACCA, J. L. de A. Um curso de astronomia e as preconcepções dos alunos. In: Revista Brasileira de Ensino de Física, v. 28, n. 1, p. 89-99, 2006. Disponível em: https://bit.ly/3da3zzz. Acesso em 17 ago. 2020.

RECEBIDO EM: 04 maio 2021

CONCLUÍDO EM: 16 set. 2021 